\title{
Sexual and Ethnic Differences in Facial Anthropometry of Northwest Indians
}

\author{
1Daisy Sahni, ${ }^{2}$ Sanjeev, ${ }^{3}$ Harjeet, ${ }^{4}$ Shallu Jaggi, ${ }^{5}$ Anjali Aggarwal
}

\section{ABSTRACT}

Aim: To determine sexual, age related and ethnic differences in somatometric measurements of Northwest Indian (NWI) and to elucidate relation between these measurements.

Context: This information will help surgeons during the planning stages of facial plastic surgery and forensic experts in reconstructing face for identification of homicide victims and missing persons.

Materials and methods: The study included 15 somatometric measurements on 173 males and 127 females healthy subjects from 18 to 70 years.

Results: Statistically significant sexual differences were observed in parameters of head, face, nose and biocular breadth and interpupillary distance. No consistent age related patterns were found except in eye and nasal regions in males. The relation between different parameters showed almost equal length and breadth of face. In majority of subjects, bigonial breadth was smaller than minimum frontal breadth but larger than face breadth. Interocular breadth was smaller than ocular and nasal breadth while nasal height and length were larger than lower face height. Ethnic comparisons render smaller values in most of the parameters.

Keywords: Somatometric measurements, Northwest India, Sexual variations, Ethnic variations.

How to cite this article: Sahni D, Sanjeev, Harjeet, Jaggi S, Aggarwal A. Sexual and Ethnic Differences in Facial Anthropometry of Northwest Indians. J Postgrad Med Edu Res 2014; 48(4):171-182.

Source of support: The study was supported by the grant from Indian Council of Medical Research, New Delhi, India.

Conflict of interest: None

\section{INTRODUCTION}

Anthropometry is a series of systematized measuring techniques that express quantitatively the dimensions of human body and skeleton. Facial anthropometry (somatometry) is a branch of anthropometry which focuses

\footnotetext{
${ }^{1}$ Professor, ${ }^{2}$ Assistant Director, ${ }^{3}$ Museum Curator

${ }^{4}$ Research Fellow, ${ }^{5}$ Assistant Professor

1,3-5 Department of Anatomy, Postgraduate Institute of Medical Education and Research, Chandigarh, India

${ }^{2}$ Department of Biology and DNA Fingerprinting, Central Forensic Institute, Bhopal, Madhya Pradesh, India
}

Corresponding Author: Daisy Sahni, Professor, Department of Anatomy, Postgraduate Institute of Medical Education and Research, Chandigarh, India, Phone: 9914208202, e-mail: daisy_sahni@rediffmail.com on measurements of face. It is extensively used in forensic medicine, forensic anthropology, craniofacial surgery, oral surgery, pediatrics and dentistry for diagnostic and prognostic comparison between the patient and normal population. An extensive work in craniofacial anthropometry has been carried out by Farkas ${ }^{1-6}$ who established database of anthropometric norms by measuring and comparing linear, angular, surface contours and proportions in North American Caucasians (NAC) over a period of many years. Several studies on anthropometry of head and face involving various syndromes and anomalies have been reported from all over the world. ${ }^{7-9}$

Anthropometric data are also applied to estimate stature $^{10,11}$ as well as to study various shapes of head and face. ${ }^{12,13}$ The use of facial anthropometric proportion indices has been studied by Edler. ${ }^{14}$ Though many studies regarding this subject have been conducted in India but very few have been reported in Northwest Indian (NWI) population. ${ }^{15-18}$ Ethnic variations often render anthropometric reference values obtained in one population unsuitable for use in others. ${ }^{19,20}$

The present study seeks to determine normal reference values, relation between different measurements and regression equations of craniofacial complex in the NWI population. Facial linear measurements were analyzed to see sexual, age related and ethnic differences. The data of the present study have applied value for plastic surgeons to make possible, an objective analysis of efficacy of surgical interventions and more accurate analysis of age related changes in facial disfigurement in patients as well as to the forensic scientists, when facial reconstruction can be the last resort when no other means of identification is available except skull.

\section{MATERIALS AND METHODS}

\section{General Procedure}

The study group consisted of 173 males and 127 females subjects between the ages of 18 and 70 years (mean age $36.3 \pm 13.4$ years). All subjects were from NWI. None had a history of previous facial trauma or cosmetic surgery. After obtaining informed consent, demographic data were obtained including age, place of birth, body weight, body height and parental heritage. Before taking measurements, surface landmarks were noted on face with a 
skin marking pencil. Measurements were obtained by using standard anthropometric methods. The following straight distances were taken on all the subjects as defined by Singh and Bhasin: ${ }^{21}$

\section{Head and Face (Fig. 1)}

1. Height of forehead (tr-n): Distance between trichion and nasion.

2. Total face height (n-gn): Distance between nasion and gnathion.

3. Upper face height (n-pr): Distance between nasion and prosthion.

4. Lower face height (sto-gn): Distance between the chin and the opening of the mouth, i.e. between stomion and gnathion. $^{22}$

5. Minimum frontal breadth ( $f t-f t$ ): Distance between the two frontotemporalia.

6. Face breadth $(z y-z y)$ : Distance between the two zygia, i.e. the most lateral points on the zygomatic arch.

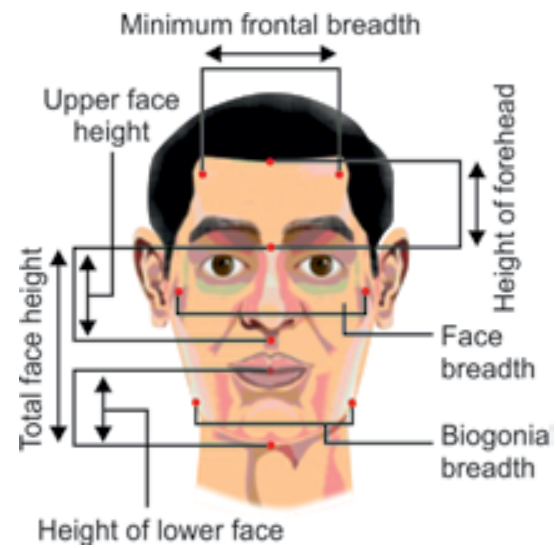

Fig. 1: Measurements on face: minimum frontal breadth (ft-ft), height of forehead (tr-n), total face height (n-gn), upper face height (n-pr), height of lower face (sto-gn), face breadth (zy-zy), bigonial breadth (go-go)

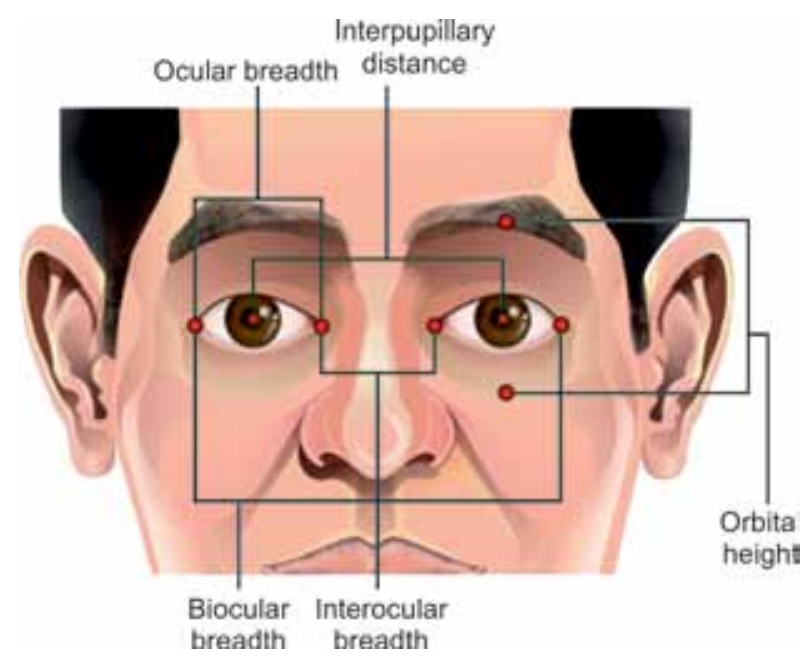

Fig. 2: Measurements on eyes: ocular breadth, i.e. distance between outer and inner canthus (en-ex), inter pupillary distance, i.e. middle of one pupil to other (pu-pu), orbital height (upper to lower orbit margin), interocular breadth (en-en), biocular breadth (ex-ex)
7. Bigonial breadth (go-go): Distance between the two gonia.

\section{Eye (Fig. 2)}

8. Biocular breadth (ex-ex): Distance between external canthi (ectocanthia), i.e. outer corners of the eye.

9. Interocular breadth (en-en): Distance between the internal canthus of the eye, i.e. endocanthion to endocanthion, with the eyelids open.

10. Ocular breadth (en-ex): Distance between endo- and ectocanthion of the same eye.

11. Orbital height: Distance between upper and lower margins of orbit.

12. Interpupillary distance ( $p u-p u)$ : Distance between the two pupilaria.

\section{Nose (Fig. 3)}

13. Nasal height (n-sn): Distance between nasion and subnasale.

14. Nasal length (n-prn): Distance between nasion and pronasale.

15. Nasal breadth (al-al): Distance between two alaria, i.e. the most laterally placed points on the nasal wings.

\section{STATISTICAL ANALYSIS}

For the present study, data were entered and analyzed on MS Office 2007 Excel spreadsheet (Microsoft Corp. Remond. WA) and SPSS 17.0 statistical software program (SPSS Inc. Chicago, IL). It was divided into five age groups; 18 to 20,21 to 30,31 to 40,41 to 50 and 51 years, and above in both sexes. Analysis of variance was performed to evaluate if there was any significant difference in measurements between gender and different age groups. Further, in order to make pairwise comparison of group means in two sexes after analysis of variance (ANOVA) was found to be significant, post hoc test called 'StudentNewman-Keuls (S-N-K)' was used which was a stepwise or layer approach to significance testing. An independent t-test was used to confirm presence of agewise sexual difference in various measurements as well as in pooled data and to investigate ethnic differences. Regression and bivariate correlation analyses were used to ascertain association between two variables. Chi-square test was applied to determine sexual difference between incidences of relation between somatometric measurements. A value of $p<0.05$ was set as being statistically significant.

\section{METHOD ERROR OF INVESTIGATION}

All measurements were taken twice by the first two authors independently on the same day. Average of two readings by two authors were taken and all repeat measurements were statistically assessed for inter observer 


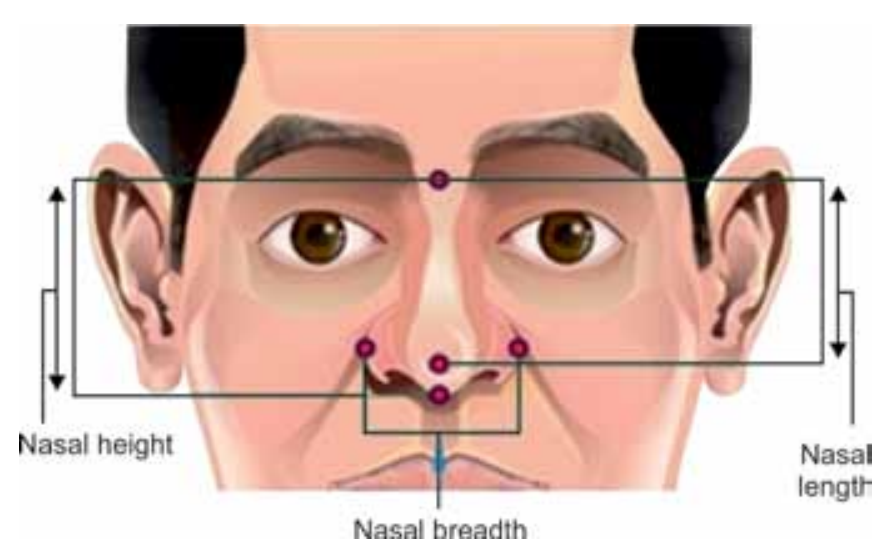

Fig. 3: Measurements on nose: nasal height (n-sn), nasal length (n-prn), and nasal breadth (al-al)

error by paired t-test; and no significant difference was found in two sets of measurements $(p>0.05)$. The reproducibility of the measurements was again confirmed by calculating technical error of measurement (TEM) in between two runs of measurements by two evaluators. The results indicated acceptable TEMs for both the evaluators suggestive of negligible technical error in the technique. Finally, average of two sets of values by both authors were calculated and used as a final reading.

\section{DATA TABLES}

Tables 1 and 2 represent the mean \pm SD of somatometric measurements $(\mathrm{cm})$ by sex and age groups (years). The relation between different somatometric variables based on their averages in two sexes is given in Table 3. The regression equations computed for various somatometric variables are given in Table 4. Data on somatometric measurements of reference population in comparison to other populations are provided in Tables 5 and 6 . Comparison of percent ratios in different ethnic groups is depicted in Table 7.

\section{RESULTS}

In the present investigation, means of all somatometric measurements were found to be significantly higher in males than females in pooled data from 18 to 70 years ( $p<0.01-0.001$ ) except interocular breadth, ocular breadth and orbital height, which were nearly equal in both the sexes. Mean values of right and left ocular breadth and orbital height differed by less than $0.5 \mathrm{~mm}$ with in each sex and age group. In females, ANOVA indicated no consistent age related patterns for various somatometric measurements except total face height and lower face height while in males age significantly influenced measurements of upper face height, all nasal parameters, interocular and ocular breadths of both sides. Results of post hoc tests further verified that after the age of 50 years all analyzed somatometric variables resumed the dimensions of the age group 18 to 30 years in both sexes except eye measurements. In the head and face region, a significant mean difference was visualized in age groups 18 to 20 years and 31 to 50 years in both males and females. Similarly, nasal parameters were comparatively larger in males of 31 to 40 years than younger and older groups while ocular breadths (right and left), were larger before 40 years of age than in older age groups ( $>40$ years) (Tables 1 and 2).

When mean values of measurements of head and face were compared with each other, minimum frontal breadth was significantly larger than bigonial breadth in $40.5 \%$ males whereas in $68.5 \%$ females it was smaller than bigonial breadth. The difference between frequencies of two sexes was highly significant $(\mathrm{p}<0.001)$. The frequency of face breadth being larger than bigonial breadth was greater in males (93.1\%) as well as in females $(83.5 \%)$ $(\mathrm{p}<0.01)$. It was further noted that upper face height was significantly larger than lower face height in $100 \%$ subjects. Interocular breadth was found to be significantly smaller than ocular as well as nasal breadth while nasal height and length were significantly larger than lower face height in more than $95 \%$ of cases. No significant difference was observed in frequencies of two sexes (Table 3).

Correlation analysis was used in conjunction with regression analysis to measure the degree of association between two somatometric variables as well as how well one variable was able to estimate another variable in two sexes. As degree of association between two variables was low in almost all the variables, so we could not be confident in estimating one variable, when the other was exactly known except in predicting face breadth and minimum frontal breadth, when bigonial breadth was known in males and females respectively (Table 4).

The beauty of face depends upon symmetry and relationship between its various components. Keeping this in view, various facial metrical ratios were calculated as shown in Graph 1. No intersexual difference was noticed in any of the facial metrical ratios, although marked sexual dimorphism was observed among various somatometric measurements in pooled data (18-70 years). Also, no change in ratios was found with age. On comparing different facial and nasal ratios in relation to total face height, it was noted that height of forehead (0.45), nasal length (0.42) and nasal height (0.45) were slightly less while upper face height $(0.60)$ was slightly more than half of the total face height in both the sexes. Lower face height (0.33) was approximately $1 / 3$ rd of the total face height. While comparing the breadths, it was found that breadth of forehead (0.93 in males, 0.90 in females) and mandible (0.93) were slightly less than face breadth whereas nasal breadth (0.29) was approximately $1 / 3 \mathrm{rd}$ of the face breadth. Total face height and face breadth showed the ratio of 0.98 indicating that length and breadth of face was 


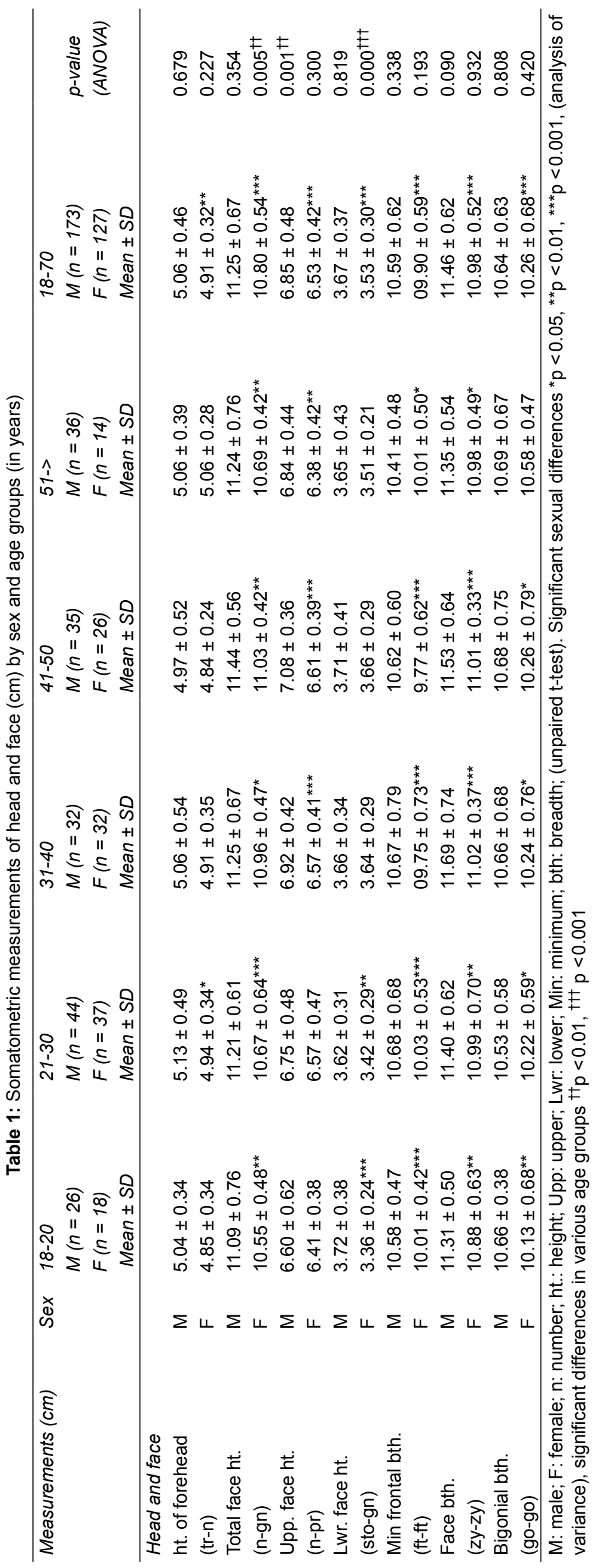




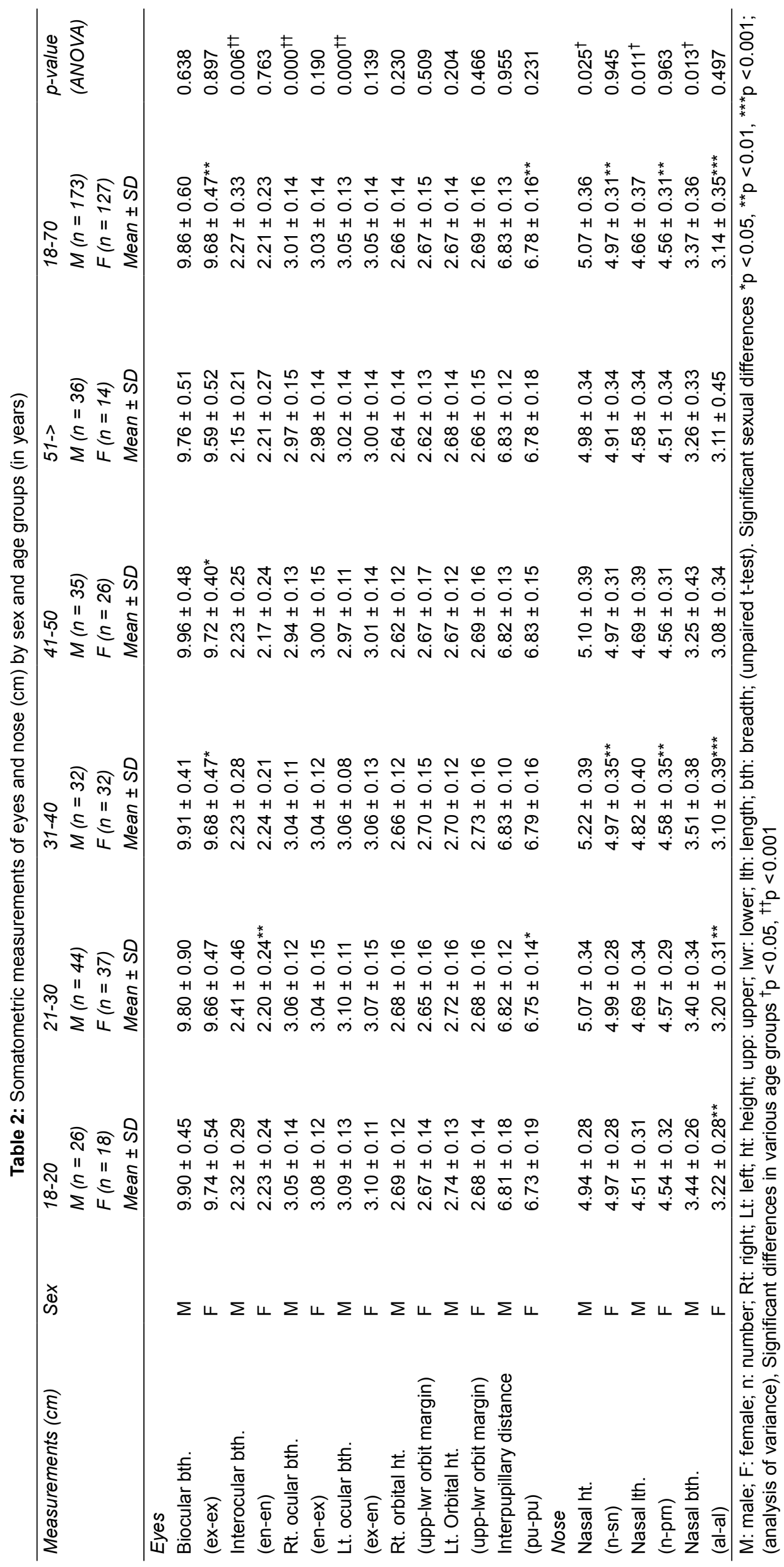




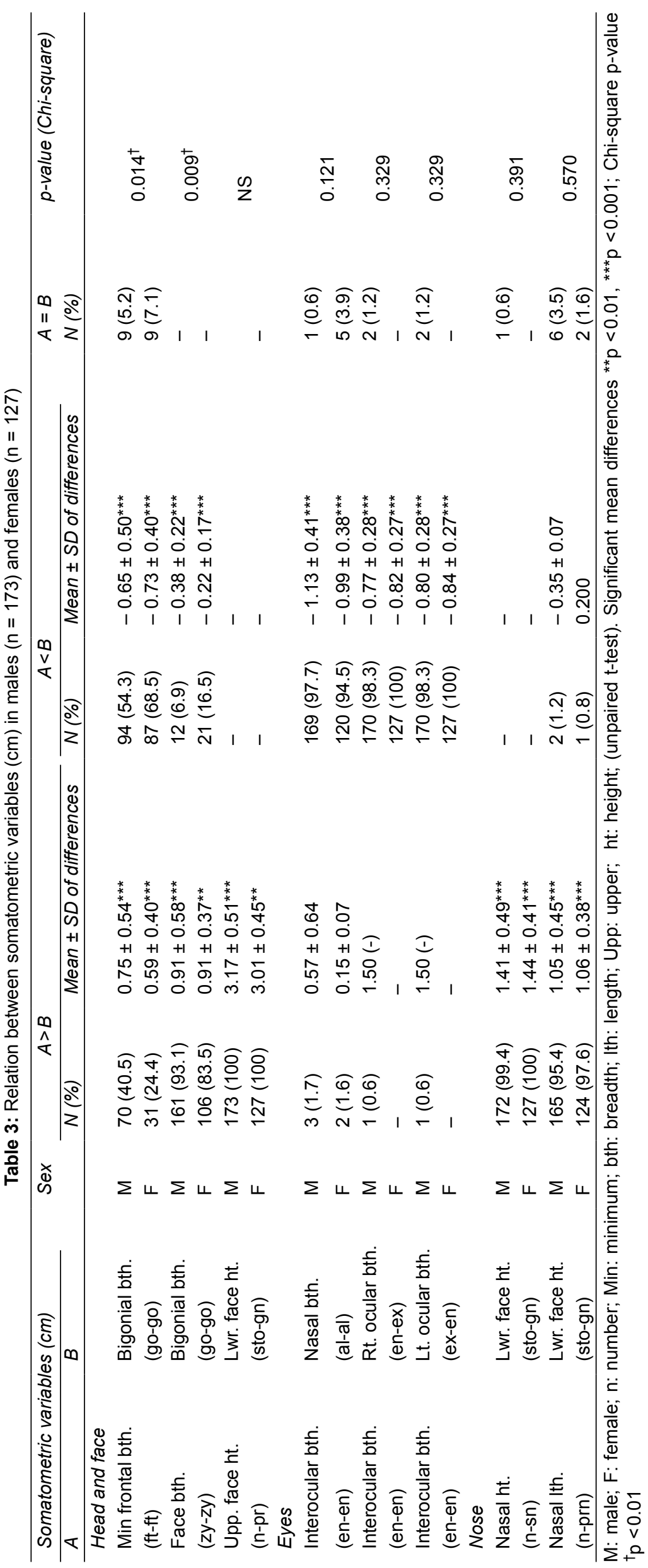



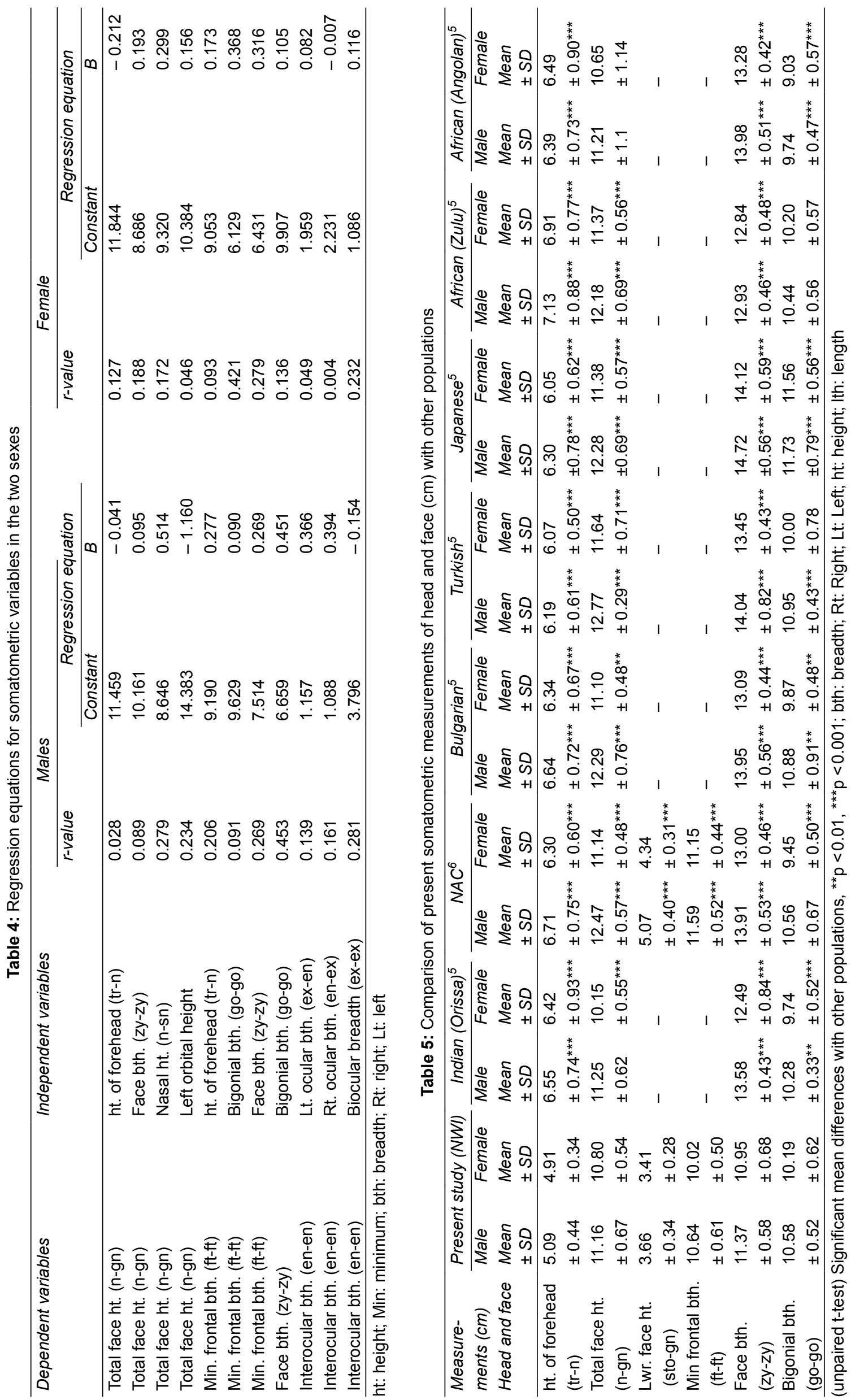


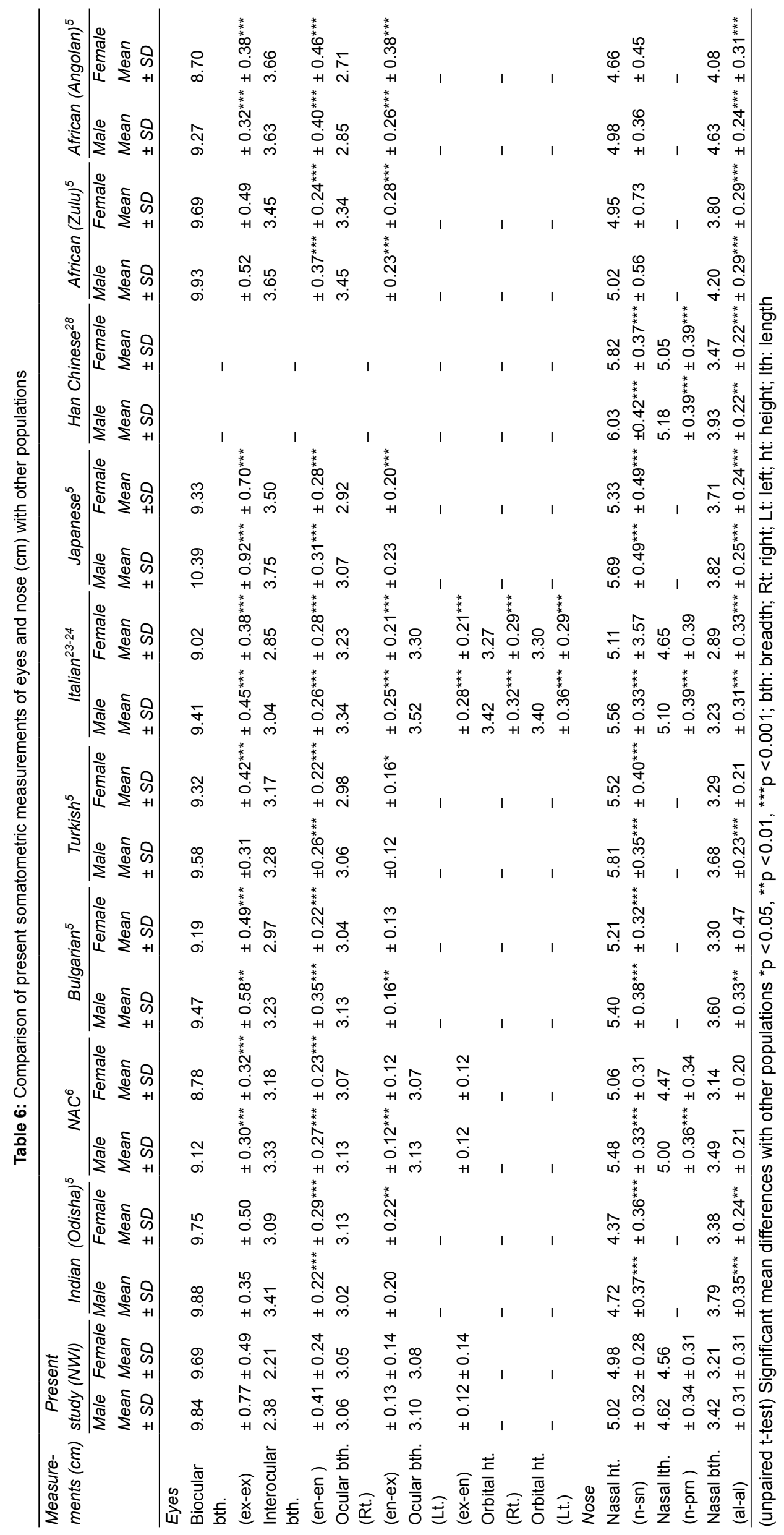




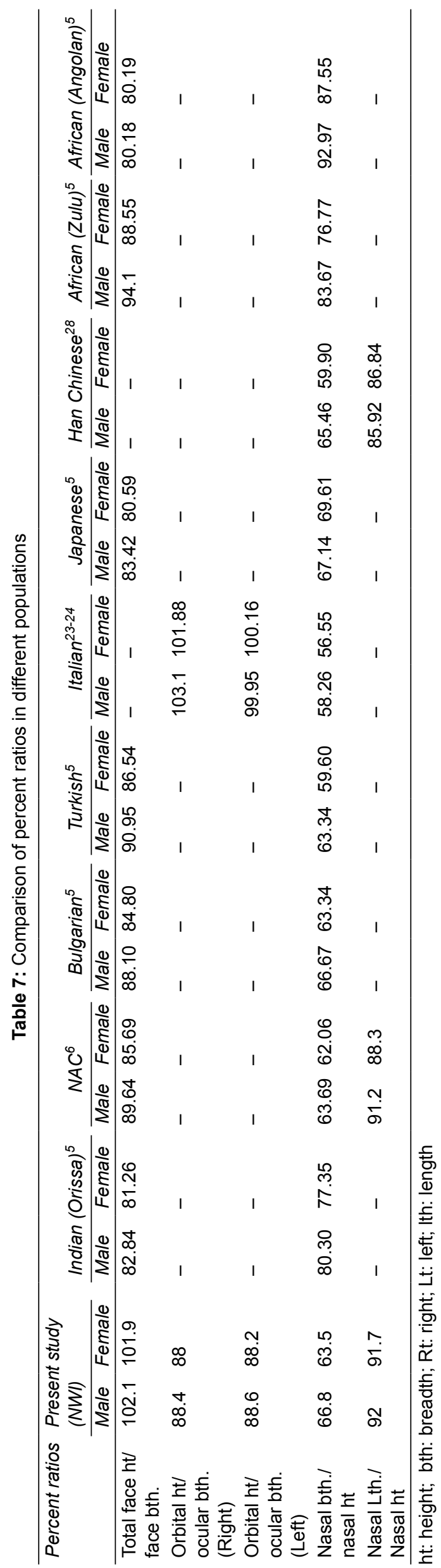




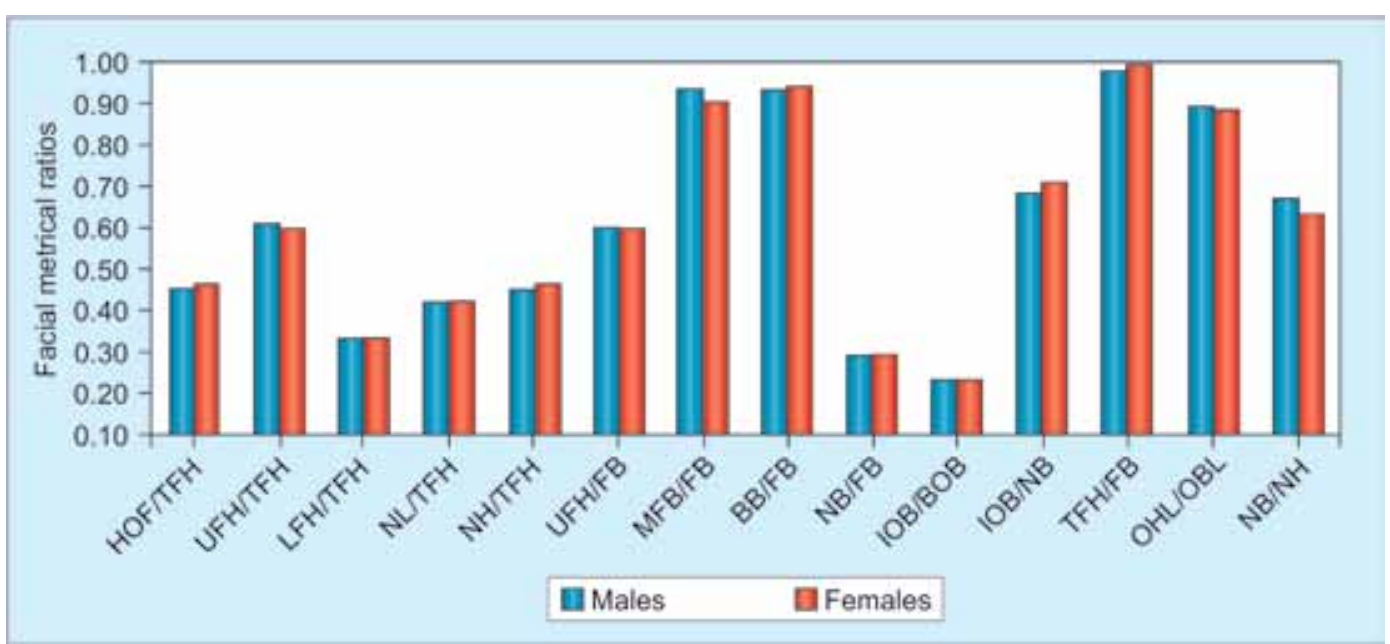

Graph 1: Histogram showing facial metrical ratios in two sexes (HOF: height of forehead; TFH: total face height; UFH: upper face height; LFH: lower face height; MFB: minimum frontal breadth; FB: face breadth; BB: bigonial breadth; NH: nasal height; NL: nasal length; NB: nasal breadth; IOB: interocular breadth; BOB: biocular breadth; OHL: left orbital height; OBL: left ocular breadth)

almost equal in NWI population. Comparatively smaller orbital height than ocular breadth was observed with symmetrical orbital ratio of 0.89 for both sides whereas nose of study population were comparatively narrower as indicated by nasal ratio ( 0.67 in males and 0.63 in females). Interocular breadth was $1 / 5$ th of the biocular breadth (0.23) whereas it was slightly more than half of the nasal breadth (0.68 in males and 0.71 in females).

\section{DISCUSSION}

Aim of the present study was to develop a satisfactory image of morphological structure of the craniofacial complex consisting of 15 somatometric measurements. These measurements were taken in an attempt to establish sexual and ethnic differences in average facial anthropometric normative data of NWI population in different age groups as well as to compute effect of age on these variables. Database of Northwestern young adult Indians in the age group of 18 to 30 years was compared with different populations of same age group. ${ }^{4-6,16,23-28}$

\section{Age Changes (Tables 1 and 2)}

In present investigation, no consistent age related patterns were observed for most of the parameters of head and face except in case of total and lower face height in females and upper face height in males. A significant increase within the facial framework emerged from 31 to 40 years and remained static till 50 years in both sexes; however, within the age group of 18 to 20 years and above 50 years an unexpected harmony was noted in values of these measurements. Whereas, in $\mathrm{NAC}^{4}$ a significant increase was observed in forehead width (minimum frontal breadth in present study) from age groups 16-20 to 21-40 years. Farkas et $\mathrm{al}^{4}$ further reported a highly significant increase in bigonial breadth from age groups of 21-30 to 31-40 years and face height from 51-60 to 61-70 years. In contrast to our findings, Kaur and Kochar, ${ }^{16}$ who explored age changes in facial framework of rural and urban Punjabi Brahmin females of Punjab (India), from 40 to 70 years, observed a decline in their mean values with aging, however, the magnitude of change was very small.

In current study, a significant modification in measurements of eyes and nose with age was observed only in males in contrast to previous study by Sforza et $\mathrm{al}^{23,24}$ in Italian Caucasoid where a significant increase was reported in both sexes. They reported a continuous increase from childhood to old age in contrast to current observations where a significant increase in nasal parameters was noted only in the age group of 31 to 40 years followed by a decline in group of $>50$ years while a significant decrease in bilateral ocular breadths was found after 40 years of age. These differences might be due to various factors like genetic, secular and ethnic which play a role in changes during aging process in facial region.

\section{Ethnic Variations (Tables 5 to 7 )}

On comparing the current observations on somatometric measurements with those reported in different racial/ ethnic groups, it was seen that discrepancy in results occurred; this might be due to ethnic and regional population diversity, use of different techniques and variable number of subjects considered for the study. Comparison of current somatometric measurements of head and face with norms established for other ethnic groups showed that most of the measurements were significantly smaller in the former than in later in two sexes. While it was interesting to note that our population had comparable values of total face height and bigonial breadth with African Angolan and Zulu groups respectively. Nasal height in both sexes also had indistinguishable values from African Zulu and Angolan groups whereas nasal 
breadth was significantly smaller than both groups. As compared to other Caucasian, Japanese and Chinese groups, nasal height was significantly smaller in study population. However, it was significantly greater than east Indians. Similarly, nasal breadth was found to be smaller except in NAC and Italian groups where both were presented with almost identical values. In comparison to Han Chinese and Italian Caucasoid mean nasal length in our series was significantly smaller. On comparing eye measurements of NWI with other ethnic groups, the biocular breadth was found to be greater than NAC, Bulgarian, Turkish, Italian Caucasoid and African Angolan groups but comparable to Indians, African Zulu in both sexes. Ocular breadth showed almost identical values to East Indian, Turkish, Japanese males and females of NAC and Bulgaria; while in Turkish and Japanese females, it was significantly greater. When compared to African groups, it was found to be significantly smaller than Zulu and greater than Angolan group. In NWI, significant greater interocular breadth was recorded than other cited populations (Tables 5 and 6).

In order to compare our data with other populations, the ratios were converted into percent ratios while for Farkas et $\mathrm{al}^{5,6}$ we calculated the required ratios from mean values (Table 7). The facial framework was expressed by the percent ratio of total face height to face breadth which was higher in our investigation than in others. This indicated that our population had comparatively longer faces as compared to other ethnic groups having medium face length. On the other hand, nasal framework, as described by percent ratio of nasal breadth to nasal height, was smaller in current study of NWI denoting comparatively narrower noses than East Indians and Africans and was comparable to NAC, Bulgarian, Turkish, Japanese and Han Chinese populations whereas percent ratio of nasal length to nasal height was greater than Han Chinese and comparable to NAC. Present study population had symmetric ratio of orbital height to ocular breadth on two sides in both sexes as compared to Turkish population. The ratio suggested a comparatively smaller orbital height than Turkish group. Based on these ratios it was noted that study population of NWI manifested some of the Caucasian features. Percent ratios of face and nose were also reported by Bhasin ${ }^{17}$ but those were not comparable to our data as he did not mention the age group.

Comparing our findings with data of NAC, ${ }^{25}$ Turkish $^{26}$ and Han Chinese ${ }^{27}$ populations, it was noted that current population of NWI had wider ocular breadth and nasal breadth in relation to interocular breadth. Though, our findings of interocular breadth being smaller than nasal breadth were in agreement with Turkish population but there was marked difference in frequencies of the two, with 97.7 and $94.5 \%$ in Indian males and females as compared to 78.9 and $50.4 \%$ in Turkish populations respectively. Similar results were recorded, when these observations were compared with NAC and Han Chinese with frequencies of 45 and $34.5 \%$ respectively. Another dominant characteristic of our population was smaller interocular breadth than ocular breadth with almost $100 \%$ occurrence as compared to approximately 50\% in Turkish population in both sexes. Whereas, larger interocular breadth was observed in majority of the subjects in NAC (42.7\%) and Han Chinese (48.3\%) populations. Symmetry in ocular breadth and orbital height was noticed for both sides within each sex and age group. Similar findings were reported by Sforza et al in Italian Caucasoid. ${ }^{24}$

\section{Sexual Differences (Tables 5 and 6)}

In current NWI population, significant sexual differences were seen in nasal measurements being greater in males than females and these results were identical to those encountered in Italian Caucasoid. ${ }^{23}$ In Chinese population, ${ }^{28}$ statistically significant sexual difference was found in nasal breadth and height but not in nasal length. Although, Farkas et $\mathrm{al}^{5}$ observed difference between means of all measurements in the males and females of different ethnic groups but they did not mention whether the sexual difference was statistically significant or not.

\section{CONCLUSION}

Present study sought to determine sexual, ethnic and age differences in somatometric measurements of NWI population. Highly significant sexual differences were found in every craniofacial region, especially in facial and nasal areas. In eye region, sexual dimorphism was noticed only in biocular breadth and interpupillary distance while no significant difference was observed when ocular breadths and orbital heights were taken separately for both sides.

Age seemed to have no effect on most of the measurements except upper face height in males; total and lower face height in females, whereas eye and nasal measurements showed modification with age only in males.

Comparison of mean values of somatometric measurements with other ethnic groups revealed comparatively lesser values in the population under study except biocular breadth. The values obtained in this study will serve as a baseline data for reference in northwest Indian population for clinical, forensic and research purposes.

\section{ACKNOWLEDGMENTS}

The authors are grateful to Director, Indian Council of Medical Research, New Delhi and Directorate of Forensic Sciences, New Delhi for financial support. They are thankful to Mr Vijay Bakshi for the illustrations and $\mathrm{Mr}$ RC Goyal for statistical analysis. Corresponding author has full access to all of the data in the study and takes 
responsibility for the integrity of the data and the accuracy of the data analysis.

\section{REFERENCES}

1. Farkas LG, Munro IR. Anthropometric facial proportions in medicine. In: Thomas CC, editor. Illinois: Springfield, 1987; 64-66.

2. Farkas LG. Anthropometry of the head and face. 2 nd ed. New York: Raven Press 1994;3-56.

3. Farkas LG. Accuracy of anthropometric measurements: past, present, and future. Cleft Palate-Craniofac J 1996;33(1):10-18.

4. Farkas LG, Eiben OG, Sivkov S, Tompson B, Katic MJ, Forrest CR. Anthropometric measurements of the facial framework in adulthood: age-related changes in eight age categories in 600 healthy white North Americans of European ancestry from 16 to 90 years of age. J Craniofac Surg 2004;15(2):288-298.

5. Farkas LG, Katic MJ, Forrest CR. International anthropometric study of facial morphology in various ethnic groups/races. J Craniofac Surg 2005;16(4):615-646.

6. Farkas LG, Katic MJ, Forrest CR. Comparison of craniofacial measurements of young adult. African-American and North American White males and females. Ann Plast Surg 2007; 59(6):692-698.

7. Allanson JE, O'Hara P, Farkas LG, Nair RC. Anthropometric craniofacial pattern profiles in Down syndrome. Am J Med Genet 1993; 47(5):748-752.

8. Farkas LG, Katic MJ, Forrest CR, Litsas L. Surface anatomy of the face in Down's syndrome: linear and angular measurements in the craniofacial regions. J Craniofac Surg 2001;12(4): 373-379.

9. Farkas LG, Forrest CR, Phillips JH. Comparison of the morphology of the cleft face and the normal face: defining the anthropometric differences. J Craniofac Surg 2000;11(2): 76-82.

10. Chiba M, Terazawa K. Estimation of stature from somatometry of skull. FSI 1998;97(2):87-92.

11. Sahni D, Sanjeev, Sharma P, Harjeet, Kaur G, Aggarwal A. Estimation of stature from facial measurements in northwest Indians. Leg Med (Tokyo) 2010;12(1):23-27.

12. Golalipour MJ, Haidari K, Jahanshahi M, Farahani RM. The shapes of head and face in normal male new borns in South-East of Caspian sea (Iran-Gorgan). J Anat Soc India 2003;52(1):28-31.

13. Golalipour MJ, Jahanshahi M, Hardari K. The variation of head and face shapes in female newborns in the South-East of Caspian sea (Iran-Gorgan). Eur J Anat 2005;9(2):95-98.
14. Edler R, Agarwal P, Wertheim D, Greenhill D. The use of anthropometric proportion indices in the measurement of facial attractiveness. Eur J Orthod 2006;28(3):274-281.

15. Jain SK, Anand C, Ghosh SK. Photometric facial analysis: a baseline study. J Anat Soc India 2004;53(2):11-13.

16. Kaur M, Kochar GK. Age related facial changes among rural and urban Punjabi Brahmin females. Ind J Gerontology 2007; 21(1):61-74.

17. Bhasin MK. Genetics of castes and tribes of India: somatometry. Int J Hum Genet 2006;6(4):323-356.

18. Bharati S Dr, Demarchi DA, Mukherji D, Vasulu TS, Bharati P. Spatial patterns of anthropometric variation in India with reference to geographic, climatic, ethnic and linguistic backgrounds. Ann Hum Biol 2005;32(4):407-444.

19. Douglas TS, Viljoen DL. Eye measurements in 7-year-old black South African children. Ann Hum Biol 2006;33(2):241-254.

20. Jahanshahi M, Golalipour MJ, Hardari K. The effect of ethnicity on facial anthropometry in Northern Iran. Singapore Med J 2008;49(11):940-943.

21. Singh IP, Bhasin MK. A manual of biological Anthropology. India: Kamla-Raj Enterprises 2004;179-183.

22. Rastogi S, Shukla BRK. Somatology In: Laboratory manual of physical anthropology (anthropometry and osteology). Lucknow: Bharat Book Centre, 2003;290.

23. Sforza C, Grandi G, Menezes MD, Tartaglia GM, Ferrario VF. Age- and sex-related changes in the normal human external nose. FSI 2010;204(1-3):205.e1-205.e9.

24. Sforza C, Grandi G, Catti Francesca, Tommasi DG, Ugolini A, Ferrario VF. Age- and sex- related changes in the soft tissues of the orbital region. FSI 2009;185(1-3):115.e1-115.e8.

25. Le TT, Farkas LG, Ngim RCK, Levin LS, Forrest CR. Proportionality in Asian and North American Caucasian faces using neoclassical facial canons as criteria. Aesth Plast Surg 2002;26(1):64-69.

26. Bozkir MG, Karakas P, Oguz O. Vertical and horizontal neoclassical facial canons in Turkish young adults. Surg Radiol Anat 2004;26(3):212-219.

27. Dawei W, Guozheng Q, Mingli Z, Farkas LG. Differences I Horizontal, Neoclassical Facial Canons in Chinese (Han) and North American Caucasian Populations. Aesth Plast Surg 1997;21(4):265-269.

28. He ZJ, Jian XC, Wu XS, Gao X, Zhou SH. Anthropometric measurement and analysis of the external nasal soft tissue in 119 young Han Chinese adults. J Craniofac Surg 2009; 20(5):1347-1351. 